\title{
10th anniversary of RESB
}

\author{
P. N. L. Lens
}

Published online: 4 March 2011

(C) The Author(s) 2011. This article is published with open access at Springerlink.com

The Journal ReViews in Environmental Science and Bio/Technology (RESB) caters for the review work of scientists, engineers and practitioners that are curious about the impact of pollution and apply measures to protect or remediate our environment. Its interest ranges from full scale bioreactors and bioremediation projects, through the scaling of metabolism, physiology and biofilms, to the fine-level molecular adaptations that allow microorganisms to function in diverse natural, man-made or engineered environments. The broad focus of RESB encompasses all disciplines of (micro)biology, bio(geo)chemistry, (colloid) chemistry, geology and (bio)process engineering.

The objectives of RESB are two-fold: (1) to bring together and synthesize the latest research results in the field and (2) to encourage more research activities in the field. With the huge amount of data/information published in the last decades in peer review journals, magazines, books and on the Web, RESB wants to contribute to make best use of these resources to mine useful data/information and to integrate these via review and mini-review papers, and in the last 2 years also via special section contributions, i.e. Horizon papers, Switch monitor, Stockholm Water Perspectives, Science Career,

P. N. L. Lens $(\square)$

Pollution Prevention and Control Core, UNESCO-IHE, PO Box 3015, 2601 DA Delft, The Netherlands e-mail: p.lens@unesco-ihe.org
Technology Career, Project Updates, Symposium Watch and Web Alerts.

The public is usually somewhat informed about environmental problems. However, people do not fully understand the basis of these problems or how to deal with them in a sustainable way. Sustainable development is a pattern of resource use that aims to meet human needs while preserving the environment so that these needs can be met not only for the present, but also for the future generations. RESB presents researchers, practitioners and senior managers with science, technology and engineering to support and enable sustainable development.

RESB started in 2001, at the time environmental science and technology focused on pollution of organic and inorganic compounds as threats to the environment and our natural heritage. The contributions mainly dealt with the human impact on the environment and scientific solutions for sustainable development. Contributions related to the human impact on the environment covered many aspects of interaction between humans, natural resources, ecosystems, special climates or unique geographic zones, and the earth. Manuscripts have covered water, air and soil pollution, soil deterioration, pesticides pollution, water resources, global warming, energy crisis, sea level rise, tropical deforestation and coral reef whitening. RESB also published on a spectrum of scientific solutions for sustainable development, such as pollution prevention, waste minimization, reuse and recycling, green chemistry, new energy and 
resource sources, energy and resource conservation, sustainable ecosystems and environmental biotechnology.

Over the 10 years of publishing RESB, pollution prevention and control is still very high on the agenda, especially in developing countries where there still a huge need for cheap effective technologies. However, several shifts in focus have been observed and new themes have emerged: climate change, energy, biomaterials and nanotechnology. The keywords People, Planet and Profit that were launched to enable environmental sustainability are tempered by a new pressure of our society onto the natural environment: the depletion of natural resources. Our environment and much of our natural heritage is now under threat from unprecedented population growth and economic development. In contrast to economic growth, our environment suffers to sustain these developments. Proper resource management is the central issue and a challenge for mankind, not only technological but also sociological. Indeed, there is growing understanding that the environmental challenges facing mankind cannot be solved solely by means of technological or societal sciences. A complex approach is needed, an approach that combines the strengths of novel developments in clean technologies and political implementation of the societal demands for sustainable development and clean environment. Environmental problems such as pollution or green house gas emissions are just symptoms of a much deeper issue: our inability to live sustainable. The scale of these problems should, however, not paralyze us into inaction. It should raise our awareness and encourage us to develop new, more sustainable patterns of living, growing, producing and consuming. Ultimately, we are talking about revaluing the fundamental elements of life. At times where money markets are looking for direction, the environment can show the way.

RESB thus contributes to communicating and disseminating the necessary answers to the questions mankind faces. We are convinced that providing broader access to the research findings and information about environmental pollution and sustainable development will be beneficial for a wide audience in academia, industry and authorities. We are therefore grateful that in its 10 years of publication, RESB has developed into a worldwide journal. Both its authorship and readership are spread all over the globe. Almost as many authors from Asian countries contribute to the journal as compared to those from Europe and US. We look forward to the work on RESB in the coming 10 years and are confident that RESB will continue to help in providing the necessary answers to the questions we face in our time.

We would like to thank all former and current members of the editorial board for their support and efforts in the development of RESB. Especially the special feature editors have played a crucial role in the diversification of RESB and took RESB a step further towards a premier league Environmental Science and Technology journal. We are also grateful to the guest editors that have edited a special issue, these have also significantly contributed to the development of RESB. Finally, we wish to thank all staff of Springer Verlag, formerly Kluwer Academic Publishers, for their enthusiastic and stimulating support, first with the establishment of the journal and later with the consolidation of this journal as a key journal in the environmental science and (bio)technology field.

Delft, February 10th 2011

Piet Lens

Editor-in-Chief

On behalf of the Editorial Board

Open Access This article is distributed under the terms of the Creative Commons Attribution Noncommercial License which permits any noncommercial use, distribution, and reproduction in any medium, provided the original author(s) and source are credited. 